\title{
Enhancing medicinal chemistry knowledge and student interest: Incorporating pharmacy practice related case studies and active-learning strategies
}

\author{
Heba Abdel-Halim \\ University of Petra, Amman, Jordan
}

\section{Keywords}

Medicinal Chemistry

Active Learning

3D Protein Visualisation

Interactive Teaching

\section{Correspondence}

Dr Heba Abdel-Halim

Department of Medicinal Chemistry

and Pharmacognosy, Faculty of

Pharmacy and Medical Sciences

University of Petra

Amman

Jordan

habdelhalim@uop.edu.jo

\begin{abstract}
Description: The action research evaluation describes a variety of novel teaching and learning techniques that were incorporated into a medicinal chemistry course. Clinically relevant medicinal chemistry cases were presented to learners complemented with 3D protein visualisation software in lectures. Evaluation: The learning outcome of students was assessed using in-class quizzes, poster session presentations and exams. Students' marks and post-course surveys were used to assess the newly employed teaching methods. The improvement in student marks complemented the post-course surveys resulted. The majority of students agreed that the course design has improved their understanding of medicinal chemistry in general and helped in relating the course to pharmacy practice. Conclusion: This study suggests that diversifying teaching and learning methods is essential to improved students' performance and understanding of medicinal chemistry. The integration of clinically relevant medicinal chemistry cases may help students to relate the concepts of drug chemistry, and drug design aspects to pharmacy practice.
\end{abstract}

\section{Introduction}

Pharmacy has always been advertised as a multidisciplinary science (Roy, 2011). Pharmacy students usually struggle to correlate the plethora of information they are exposed to during their years of study, and usually lack the understanding of the value, and importance of many of the topics they are studying. It is more challenging to demonstrate the significance of basic science courses, including medicinal chemistry, to students that are more interested in clinical, and pharmacy practice oriented courses. It is essential to integrate the clinically relevant medicinal chemistry with other pharmacy curriculum courses (Beleh et al., 2015). Many factors were previously reported to impact students' learning and understanding of medicinal chemistry which is usually perceived as a difficult, hard to comprehend, and clinically irrelevant course (Alsharif et al., 2008).

Medicinal chemistry is a chemistry discipline that also includes aspects of biological, medical, and pharmaceutical sciences (Wermuth et al., 1998). In Jordan, medicinal chemistry is a mandatory part of the pharmacy degree curriculum. Most courses are traditional medicinal chemistry courses that focus on drug chemistry, and the structure activity relationship (SAR) of chemically related compounds that share the same activity.

With the increasing number of students enrolling in the classes, lecturing remains the prevalent method of teaching, as interactive teaching is not always easy. 
However, the incorporation of active-learning approaches were proven effective in the teaching of medicinal chemistry, and improved students communication skills (Carvalho et al., 2005).

The aim of this paper is to show how the introduction of practice-related cases into the medicinal chemistry lectures has improved students' views of the importance of medicinal chemistry in the pharmacy profession. Examples form the lectures are presented here, each case stressing the association of the drug's chemistry to the different factors that influences the therapeutic outcomes, method of manufacturing, and/or route of administration. Furthermore, an innovative teaching methods that allowed more integrative learning opportunities to students were introduced to the course, and great improvement in the students' performance was observed.

\section{Description of course}

This study follows the update and transformation of the medicinal chemistry course over five years. The shift from traditional medicinal chemistry topics, and the expansion of new teaching methods was instigated. Interactive teaching methods were employed, and case studies that included some practice-related issues that pharmacists might encounter in practice were used to familiarise students with the importance of medicinal chemistry, and to increase their interaction and interest in the lectures.

Six major areas of pharmacy-related scenarios were identified to be of high association with medicinal chemistry:

1. Drug pharmacokinetic properties

2. Drug route of administration

3. Drug formulation

4. Drug-drug interactions

5. Target binding

6. Side effect profile.

Sample cases were developed to cover the mentioned topics, and a variety of interactive teaching and learning methods were used during the medicinal chemistry lectures. The medicinal chemistry course is divided into chapters according to the mechanism of action of drug class; each chapter is designed so that the mechanism of action, and chemical aspects of the drug class are clarified at the start; subsequently, detailed SAR is explained, and the importance of structural modification to the mode of action is elucidated. When available, 3D presentations of the drug bound to its site of action are shown to students using freely available 3D visualising software. To raise students' enthusiasm and appreciation of medicinal chemistry one or more of the six mentioned topics are covered in each chapter. To further increase students' interaction and involvement, questions are asked during the class in the form of 'Post-it Note' quizzes, or at the end of the chapter in the form of printed quizzes, and in the different exams. When marking quizzes, students with correct answers, or with wrong answers but correct way of thinking, were awarded bonus marks for their attempts.

\section{Case Studies}

The following case study examples were directly extracted from medicinal chemistry lecture notes. Teaching slides are made available for students before the lectures. Many other cases were also used however, but are not included in this work.

\section{Case Study 1: Opioids}

All aspects of opioids' SAR were explained using morphine as an example. One of the most important factors is the ionisation state of the amine group; the amine group is a weak base and morphine would exist both as the free base and the ionised forms at physiological $\mathrm{pH}$. Morphine, and other opioids, cross the blood-brain barrier (BBB) as the free base then ionise to form the positive charge essential for interaction with the opioid receptors. Only a small percentage of the dose administered reaches the receptors in the central nervous system (CNS) (Fong, 2015).

The students were presented with the structures $A, B$, and $C$ in Figure 1, and were asked to determine the opioid more available in the CNS. Some students recognised that structure A (normorphine) had a missing hydrophobic $\mathrm{CH} 3$ group (more polar compound) therefore may have less chance to cross the BBB, which is true as normorphine processes $25 \%$ to the activity of morphine. For compounds $\mathrm{B}$ and $\mathrm{C}$, after explaining the effect of introducing an ester group to mask the polar-OH groups, most of the students determined compound $C$ (diamorphine, heroin) to be more active and readily available in the CNS than compounds A and B (6acetylmorphine). Once the two prodrugs are in the CNS both will be hydrolysed to morphine to bind to the opioid receptors. Additionally, students were shown the $\mathrm{N}$-methyl quaternary salt of morphine (Figure 1D), which is inactive when administered by intravenous injection. 
This fully charged morphine analogue cannot cross the $\mathrm{BBB}$, and is only active if injected directly into the CNS and shows a similar activity to that of morphine.

For more emphasis on students' understanding of the importance of chemical structure on a drug's pharmacokinetics, and its effect on drug action, students were handed the quiz in Appendix A. The majority of students were able to determine that the drug is an antagonist and it will act only in periphery as it cannot cross the BBB. These students suggested therapeutic uses of the drug by acting on opioid receptors outside the CNS. However, some students kept the original use of the drug but suggested direct injection into the CNS. Both answers were considered correct.
A: Normorphine
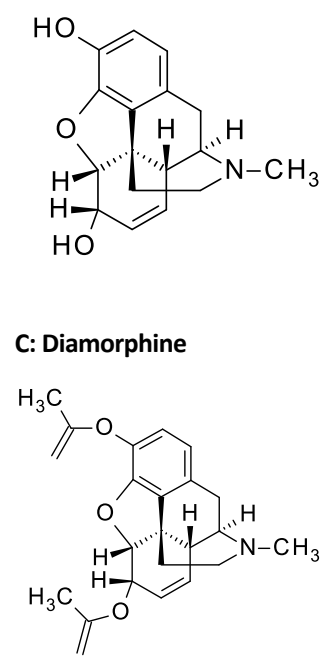

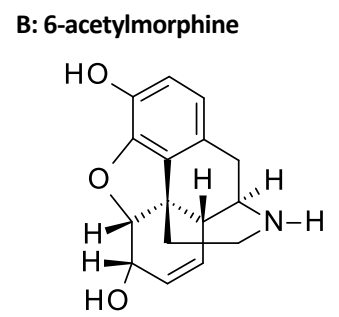

D: N-methyl quaternary salt of morphine

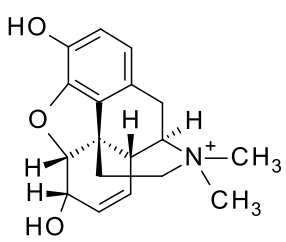

Figure 1: Morphine analogues

\section{Case Study 2: Non-steroidal anti-inflammatory drugs}

Students in this chapter were introduced to protein isoforms and the differences observed in amino acid residues lining the active site that may influence the drug binding and/or action.

Non-steroidal anti-inflammatory drugs (NSAIDs) target cyclooxygenase (COX) enzyme and inhibit prostaglandin synthesis. The enzyme exist mainly in two isoforms, COX-1 and COX-2; the binding sites of both isoforms are very similar in structure with the binding site of COX-2 almost $25 \%$ larger than the COX-1 binding site (Vane et al., 1998). The difference in the binding sites of COX-1 and COX-2 was explained to students and the influence of the NSAID chemical structure and size on binding to COX-2 and not
COX-1 was elucidated (Lemke et al., 2007). Both enzyme subtypes have different physiologic functions due to the differences in their site of expression and regulation. COX-1 is expressed constitutively in almost all tissues and is responsible for the production of prostaglandins important for homeostatic functions, while COX-2 is up-regulated during inflammation. Therefore, the implications of NSAIDs targeting any of the enzyme isoforms was emphasised and the impact of NSAIDs chemical structure on therapeutic decision-making was established (Crofford, 1997).

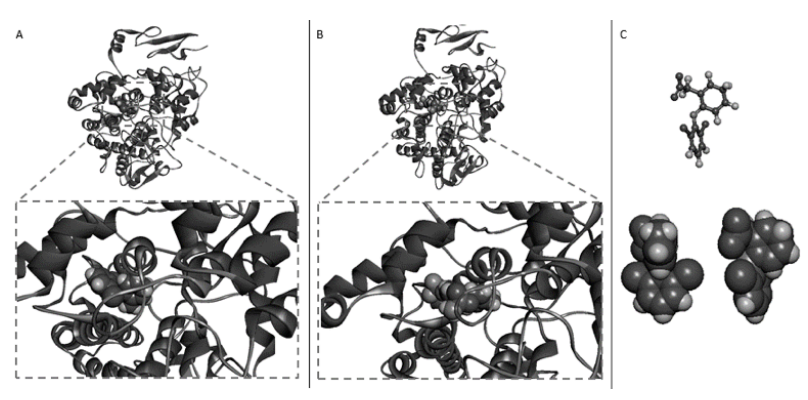

Figure 2: 3D structures

A: 3D Crystal structure of diclofenac in the COX-1 binding site (PDB Code: 3N8Y [Sidhu et al., 2010[]

B: 3D Crystal structure of celecoxib bound to COX-2 (PDB Code: 3LN1 [Wang et al., 2010])

C: $3 \mathrm{D}$ structure of diclofenac as bound within COX-1 active site, showing the noncoplanar conformation of aromatic rings.

Figure generated using Discovery Studio Visualizer (Dassault Systèmes BIOVIA)

The 3D structures of COX-1 bound to diclofenac (PDB code: 3N8Y, (Sidhu et al., 2010)), and COX-2 bound celecoxib (PDB code: 3LN1, (Wang et al., 2010)) were presented to the students in the lecture using Discovery Studio Visualizer (Dassault Systèmes BIOVIA). The difference in ligand binding is explained (Figure 2: $A$ and B). Students, by visualising the ligand-receptor complex, became familiar with the preferred intermolecular interactions of NSAIDs within the binding site of the receptor. Moreover, they were able to recognise the correct orientation of the drug within the COX active site, the non-coplanar conformation of aromatic/lipophilic functional groups as restricted by the COX binding site residues (Lemke et al., 2007). This non-coplanar orientation of rings is important for optimal binding to the receptor as seen in the diclofenac molecule conformation as extracted from its binding site (PDB code: $3 \mathrm{~N} 8 \mathrm{Y}$, (Sidhu et al., 2010)) (Figure 2: C). 
<smiles>Cc1cccc(Nc2ccccc2C(=O)O)c1C</smiles>

Meclofenamic acid<smiles>Cc1ccc(Cl)c(Nc2ccccc2C(=O)O)c1Cl</smiles>

Figure 3: Structures of $\mathrm{N}$-arylanthranilic acids

The structures of $\mathrm{N}$-arylanthranilic acids, meclofenamic acid and mefenamic acid, (Figure 3) were shown to students and they were asked to predict the compound that possesses more activity. Students were asked to draw the structure of the more active compound on a 'Post-it Note' and to highlight the group's responsible for this increase in activity before handing in their notes for marking. Once all notes are collected, side discussions for about two minutes among the students were allowed; afterwards the correct answer was given to students. Most of the students would recognise the steric effect of the two o-chlorine atoms in the meclofenamic acid to maintain the non-coplanar conformation of aromatic groups and thus the increased activity observed over mefenamic acid.

Approximately half of the marketed drugs are administered in the form of salts. Despite the significant improvement of drug's physicochemical properties when administered in the salt form, a proper salt should be selected for a drug molecule to ensure the optimal therapeutic outcome (Gupta et al., 2018). The type of salt of any active drug molecule would highly affect the physicochemical and/or the biological properties of this drug, and different salt forms of the same drug can be used for different routes of administration.

The acidic group of NSAIDs is part of their pharmacophoric nucleus, the anionic conjugate base is essential to anchor to the cationic arginine residue within the COX binding site. Generally, this acidic group is beneficial for formulating NSAIDs into their corresponding salt forms.

Diclofenac was given as an example of the significance of the type of salts used on drug properties. The sodium, potassium, and the free acid forms are used in oral preparation, while diclofenac sodium is used in topical preparations (gel and solution). In addition the epolamine salt is used as a transdermal patch due to its better skin permeation than the sodium or potassium salts (McPherson et al., 2013). The potassium salt and free form of diclofenac are characterised by immediate release and hence they are known for a quick onset of effect, while the sodium salt form is used in the extended release dosage form (Fini et al., 1996).

After explaining the effect of the type of salt on the pharmacokinetics of the drugs in general, students were asked to select the most appropriate diclofenac form to be used for the following patients:

1. Male patient suffering from rheumatoid arthritis

2. Female patient admitted to the emergency room for dysmenorrhea

3. Geriatric male patient with complicated heart condition.

In this case, I would ask one student to give his/her therapeutic choice for one of the cases. A quick poll for the whole class by 'show of hands' of the suggested treatment after the student's suggestion is carried out. Any student that was against the regimen chosen is asked to justify his/her reason to disagree to the class.

In summary, I would emphasise that for patients using diclofenac for chronic conditions the onset of action between various products is unlikely to be clinically significant (male with rheumatoid arthritis). However, once an immediate and quick effect is required, diclofenac potassium is the drug of choice (female with dysmenorrhea). Furthermore, patients with concerns about blood potassium levels should avoid using diclofenac potassium products (geriatric male with complicated heart condition). Although the low potassium content of some products may not pose any threat to patients' health, usually patients with renal failure or on angiotensin-converting enzyme inhibitors, angiotensin receptors blockers, or potassium sparing diuretics should avoid all systemic NSAIDs not just diclofenac potassium products (Varga et al., 2017).

\section{Case Study 3: Proton pump inhibitors}

All proton pump inhibitors (PPIs) are prodrugs activated by molecular rearrangement in the strong acidic environment of the parietal cell canaliculus. Once activated these compounds irreversibly bind to the $\mathrm{H}+/ \mathrm{K}+-$ ATPase, and disable the catalytic function of the proton pump. Disulfide covalent bond(s) are formed between the activated drug molecule and cysteine residue(s) in the cysteine-rich $\mathrm{H}+/ \mathrm{K}+-A T P a s e$ (Cys813 and/or, Cys892, Cys822), different interactions are observed among different PPIs (Figure 4) (Lemke et al., 2007; Shin, 2011). PPIs differ in their binding mode than the majority of known drugs and natural substrates. This is one of few 
examples of a drug binding irreversibly to the active site, previous examples in the course showed that most drugs interact through weaker intermolecular bonds with an equilibrium between the drug bound and unbound to its target. The strength of the covalent bond would mean a stronger, and longer duration of action of the drug which depends on how quickly new pumps would be generated by the cell.

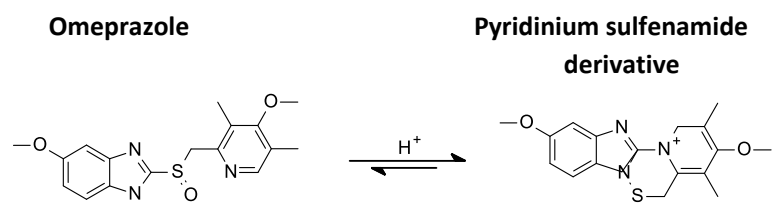

Figure 4: The mechanism of activation of PPIs, omeprazole as example

Only the inactive prodrug and active pyridinium sulfenamide forms of omeprazole are shown.

The importance of stereochemistry of the drug and the effect on activity had been explained in previous chapters. PPIs do not have an evident chiral centre, however the sulfur atom is an asymmetric atom as it has a lone pair of electrons with a tetrahedral geometry (Figure 5) (Lemke et al., 2007). After explaining this fact, students were asked if the different PPI enantiomers would have different activities (my hint: refer to Figure 4). The majority of students do not answer this one right, I follow this with the question: 'Do we still have the same sulfur in the active pyridinium sulfenamide derivative (i.e. is the sulfur bound to four different atoms)?'. At this point it becomes clear that the active form is achiral and therefore the stereochemistry of the prodrug will not affect the binding of the drug to its target.

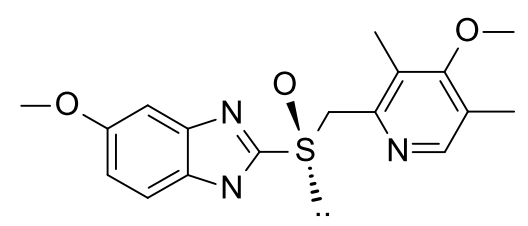

Figure 5: Omeprazole structure showing the sulfur chirality

The next question would be: 'Why do we have S-enantiomer of omeprazole in the market?'. Many times, I would get this question from students directly after explaining the insignificance of stereochemistry of PPIs, but if not, I would ask it myself.

The S-enantiomer (esomeprazole) was found to have a better pharmacokinetic profile; it has a lower clearance rate and is less metabolised than omeprazole resulting in higher plasma levels. Therefore, it is possible to use double the dose levels of esomeprazole leading to increased activity (Johnson, 2003).

In general, enzymes involved in metabolic reactions will distinguish between the two enantiomers of a chiral drug, Hence, metabolites of different stereoisomers must be identified and tested separately as the therapeutic outcome and/or pharmacokinetics of using enantiomer pure formulation may differ (Patrick, 2017).

PPIs are absorbed in their inactive form and are only activated after being secreted into the gastric lumen to reach the strongly acidic environment of the canaliculus (Shin, 2011). At this point, I would ask students to suggest the best formulation for PPIs. Almost always one or two students in the class would answer that all PPIs come in enteric coated tablets or capsules. My next question would simply be 'Why?'.

In very few cases I could get an answer; students who know this fact were exposed to it in other courses without knowing the need to have this pharmaceutical form. The enteric coat is required as PPIs should reach their site of action unchanged to exert their effect. If they were administered in immediate release tablet form they would be exposed to the acidity of the stomach lumen and would be immediately activated prior to reaching the proton pumps. Higher $\mathrm{pH}$ in the intestine, and the blood ensures stability of the drug until it diffuses back across the gastric membranes to reach the canaliculus.

Based on the PPIs activation in the canaliculus, I would ask students to predict their side effect profile (my hint: site of action with lowest $\mathrm{pH}$ in the body). A good consensus among students that PPIs would have good safety because of their selectivity of action, especially as they are only activated once they reach the target enzyme that is only present in parietal cells.

\section{Case Study 4: Benzodiazepines}

Polar compounds are more readily excreted by the kidneys than non-polar drugs that need to be metabolised and converted into more polar molecules to be easily excreted.

The lipophilicity of benzodiazepine depends on the nature of substituents that will lead to the differences in the 
physicochemical and pharmacokinetic properties observed in different compounds. Most benzodiazepines have relatively high $\log P$ values resulting in high oral bioavailability, and rapid distribution to the brain and other highly perfused organs. In addition, most benzodiazepines and their metabolites bind to plasma proteins, $99 \%$ of lipophilic benzodiazepines are bound to plasma proteins versus only $70 \%$ for more polar derivatives.

The question here: 'How does benzodiazepines' physicochemical properties fit their therapeutic use?'. This is an easy one for all students; benzodiazepines are covered in the third chapter of drugs affecting the CNS, the answer would be that ALL benzodiazepines should be lipophilic to reach their site of action in the CNS (Fong, 2015).

Benzodiazepines are subject to hepatic oxidation by a variety of cytochrome $P$ enzymes, metabolism includes $\mathrm{N}$-dealkylation and aliphatic hydroxylation. Subsequently these metabolites are conjugated by glucuronyl transferases to yield polar glucuronides to be excreted in urine. The duration of action, and metabolite formed vary depending on the route of administration and the individual drug.

Diazepam (Figure 6) is a highly lipophilic compound rapidly and completely absorbed after oral administration with slow elimination and a half-life of approximately 20 to 50 hours. The major metabolic product of diazepam is $\mathrm{N}$-desmethyldiazepam which is pharmacologically active, and undergoes slower metabolism through hydroxylation at the 3-position to give the active metabolite oxazepam. Oxazepam (Figure 6), on the other hand, is marketed separately and has a half-life of four to eight hours.<smiles>CN1C(=O)CN=C(c2ccccc2)c2cc(Cl)ccc21</smiles><smiles>O=C1Nc2ccc(Cl)cc2C(c2ccccc2)=NC1O</smiles>

Figure 6: Structure of benzodiazepines highlighting the metabolism sites

The question here: 'Why does oxazepam have a short duration of action (short half-life) than diazepam?'. Some students would get this one easily; oxazepam is an intermediate in the metabolic pathway of diazepam, and therefore it is rapidly inactivated to glucuronidated metabolite excreted in the urine resulting in its short duration of action.

The question now would be how to select the proper benzodiazepine based on the clinical case presented to you. This is not an easy case for the students but at this point they can predict the duration of action of the benzodiazepine molecule from its chemical structure. For optimum therapeutic outcome, short-acting benzodiazepines that are rapidly metabolised to inactive products should be considered in hepato-compromised patients, as the therapeutic and toxic effects of long-acting benzodiazepines may persist several days after discontinuation chronic treatments.

\section{Case Study 5: Aminoglycosides and Penicillins:}

Clinically, aminoglycosides are used in combination with $\beta$-lactam antibiotics due to their synergistic bactericidal effect. Both antibiotics are given intravenously and students are asked if there are any concerns related to giving them in the same solution. I start by asking the question without showing the structures to the students, this case is presented at the end of the aminoglycosides course, $\beta$-lactam antibiotics were covered earlier in the semester.

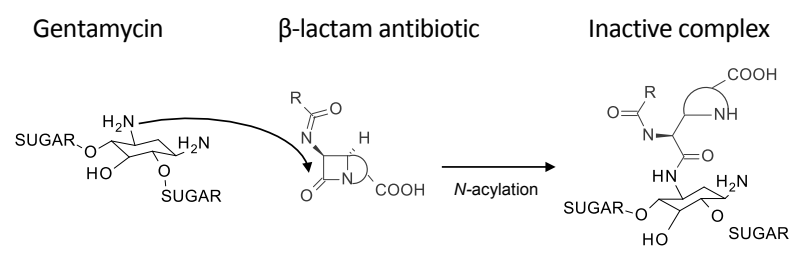

Figure 7: Chemical drug-drug incompatibility between gentamicin C-2a and $\beta$-lactam antibiotics

I usually would have a quick 'show of hands' poll then I show the two antibiotics to students. I ask them to predict any functional groups that may interact together. Usually the first answer would be the $\beta$-lactam ring in penicillin. All students at this point are familiar with the stained nature of the ring which makes it susceptible to cleavage by various nucleophiles, acid or base reagents, metal ions, oxidising agents or alcohol (Deshpande et al., 2004). Some students would pick the presence of nucleophilic amines in the aminoglycoside and would conclude that the two compounds are chemically incompatible due to nucleophilic attack of the amine group to the carbonyl of 
the $\beta$-lactam ring. The reaction in Figure 7 is shown to students where $\mathrm{N}$-acylation on $\mathrm{C}-\mathrm{I}$ of gentamicin by $\beta$-lactam antibiotics inactivates both antibiotics. Therefore, the two agents should not be mixed and should be administered into different sites to prevent this interaction. (Wallace et al., 1985). This is a clear example of chemical incompatibly that can be easily picked up by just looking at the structure.

\section{Case Study 6: Local anaesthetics}

The ideal local anaesthetic should have rapid onset of action, sufficient duration of action, no systemic toxicity, can be easily sterilised, and not expensive. They are available in various dosage forms such as aqueous solutions for injection, and topical creams and ointments. Local anaesthetics show a diversity in chemical structures that directly affects their pharmacokinetic properties and are essential factors to achieve the suitable pharmaceutical dosage forms (Lemke et al., 2007).

The SAR of local anaesthetics is explained to students highlighting the important facts. In general, the amide linkage (lidocaine analogs) have greater chemical stability than compounds containing an ester bond (procaine analogs). In addition, substitution of the aromatic ring mainly on the ortho-position provides steric hindrance that protect from hydrolysis, and ensures a desirable duration of action.

Local anaesthetic activity increases with increasing lipid solubility, however this increase would affect water solubility required for parenteral dosage forms. Compounds with basic aliphatic amino are formulated in their salt forms to provide the required water solubility for injections.<smiles>CCN(CC)CCOC(=O)c1ccc(N)cc1</smiles>

Procaine<smiles>CCCCN1CCCC(C(=O)Nc2c(C)cccc2C)C1</smiles>

Figure 8: Local anaesthetics
Student were shown the structures of local anaesthetics (Figure 8) and were asked two questions:

1. Order the shown local anaesthetics according to their duration of action; and

2. Select the compound that is not appropriate for parenteral administration.

Answers are collected on 'Post-it Note' and class discussion would follow as was previously mentioned.

The order of duration of action is a match of the compound's chemical stability; amino amides are more resistant to hydrolysis than amino esters, thus they are expected to have longer duration of action. In addition, the branching on the aromatic rings (o-substitution) will increase the stability and thus prolong the duration of action.

Benzocaine is insoluble in water as it lacks the basic aliphatic amino group needed for salt formation, therefore no pharmaceutically acceptable parenteral preparation is available and can only be used in creams, or ointments.

\section{Evaluation}

\section{Survey}

Students' interest in the medicinal chemistry course has increased as was observed in the class; the interaction among students and their enthusiasm during cases presentation was beyond expected. The effect of the changes in the course was further measured by surveying students. Survey statements were designed to assess the student feedback on the importance of linking medicinal chemistry to pharmacy practice.

Some previous studies have measured the impact of incorporating active learning techniques (Satyanarayanajois, 2010), and adding clinically relevant cases in medicinal chemistry (Alsharif et al., 2008); however none of the used assessment tools suited this study. Therefore, we developed a survey based on views of students throughout the course and influenced by some students' verbal feedback in and outside the class; survey statements are listed in Table I. Students were evaluated in a three-point Likert scale using 'agree' to 'disagree' where answer ' 3 ' was considered neutral.

All medicinal chemistry students were asked to fill in the questionnaire, with an option not to participate and no 
Table I: Results of medicinal chemistry course evaluation survey

\begin{tabular}{|c|c|c|c|}
\hline \multirow{2}{*}{ Question } & \multicolumn{3}{|c|}{ Student Response: N: 270 (\%) } \\
\hline & Agree & Neutral & Disagree \\
\hline \multicolumn{4}{|l|}{ The following questions are about the medicinal chemistry course: } \\
\hline The layout of the course is suitable & $183(67.7 \%)$ & $24(9.0 \%)$ & $63(23.3 \%)$ \\
\hline The number of quizzes (different types) were sufficient & $247(91.5 \%)$ & $4(1.5 \%)$ & $19(7.0 \%)$ \\
\hline The 'Post-it Note' quizzes were effective in increasing your attention in the class & $270(100 \%)$ & $0(0 \%)$ & $0(0 \%)$ \\
\hline The course increased your interest in medicinal chemistry & $92(34.1 \%)$ & $130(48.1 \%)$ & $48(17.8 \%)$ \\
\hline The course increase your ability to identify functional groups important for drug activity & $260(96.3 \%)$ & $3(1.1 \%)$ & $7(2.6 \%)$ \\
\hline The course improved your critical thinking and problem solving skills & $176(65.2 \%)$ & $39(14.4 \%)$ & $55(20.4 \%)$ \\
\hline $\begin{array}{l}\text { The knowledge gained from this course will be help me relate the chemistry of the drug to its } \\
\text { pharmacological effect }\end{array}$ & $263(97.4 \%)$ & $6(2.2 \%)$ & $1(0.4 \%)$ \\
\hline $\begin{array}{l}\text { The examples covered in the lectures were relevant to other courses in the Pharmacy } \\
\text { curriculum }\end{array}$ & $264(97.8 \%)$ & $6(2.2 \%)$ & $0(0.0 \%)$ \\
\hline $\begin{array}{l}\text { The course helped you understand some concepts covered in other courses in the Pharmacy } \\
\text { degree curriculum }\end{array}$ & $201(74.4 \%)$ & $8(3.0 \%)$ & $61(22.6 \%)$ \\
\hline \multicolumn{4}{|l|}{ The following questions are about the pharmacy practice case studies used in the lectures: } \\
\hline $\begin{array}{l}\text { Pharmacy practice cases presentation method was helpful in understanding the importance of } \\
\text { medicinal chemistry }\end{array}$ & $190(70.4 \%)$ & $52(13.3 \%)$ & $28(10.4 \%)$ \\
\hline Time taken to explain clinical cases was sufficient & $80(26.6 \%)$ & $10(3.7 \%)$ & $180(66.7 \%)$ \\
\hline $\begin{array}{l}\text { Pharmacy practice related questions and revisions were helpful in understanding the topic and } \\
\text { preparing for the exams }\end{array}$ & $184(68.2 \%)$ & $2(0.7 \%)$ & $84(31.1 \%)$ \\
\hline Pharmacy practice cases were relevant to other courses in the pharmacy curriculum & $230(85.2 \%)$ & $0(0.0 \%)$ & $40(14.8 \%)$ \\
\hline $\begin{array}{l}\text { The knowledge gained from this course will be help you relate the chemistry of the drug to } \\
\text { pharmacy practice }\end{array}$ & $228(84.4 \%)$ & $3(1.1 \%)$ & $39(14.2 \%)$ \\
\hline $\begin{array}{l}\text { Pharmacy practice cases, where appropriate, should be integrated in other medicinal chemistry } \\
\text { courses }\end{array}$ & $255(94.4 \%)$ & $10(3.7 \%)$ & $5(1.9 \%)$ \\
\hline $\begin{array}{l}\text { Pharmacy practice cases should be included in other pharmacy curriculum basic sciences } \\
\text { courses }\end{array}$ & 259 (95.9\%) & $0(0.0 \%)$ & $11(4.1 \%)$ \\
\hline Pharmacy practice cases gave me insight into more roles that can be played by the pharmacist & $268(99.3 \%)$ & $2(0.7 \%)$ & $0(0.0 \%)$ \\
\hline $\begin{array}{l}\text { Pharmacy practice cases emphasized the role of pharmacist as the drug chemistry expert in the } \\
\text { medical team }\end{array}$ & $253(93.7 \%)$ & $9(3.3 \%)$ & $8(3.0 \%)$ \\
\hline Pharmacy practice cases made me think like a health care professional & 268 (99.3\%) & $1(0.4 \%)$ & $1(0.4 \%)$ \\
\hline $\begin{array}{l}\text { Interactive teaching methods helped in helpful in understanding the topic and preparing for the } \\
\text { exams }\end{array}$ & $104(38.5 \%)$ & $13(4.8 \%)$ & 153 (56.7\%) \\
\hline Interactive teaching methods should be included in different course & $164(60.7 \%)$ & $8(3.0 \%)$ & $98(36.3 \%)$ \\
\hline
\end{tabular}

incentives were offered. However, students were informed that participating in this survey will provide feedback to further improve the course. At the end of the course, students who agreed to participate in the survey completed this anonymously. The average number of students in the medicinal chemistry course is 130 student per semester. From around 780 students, the questionnaire was answered by 270 students. A sample size of 258 was needed to find sense in the study at a confidence level of $95 \%$ with a margin of error of $5 \%$. Students with different GPAs range participated in the survey. The survey results (Table I) shows that more than half $(67 \%)$ of the students were satisfied with the course layout. The incorporation of pharmacy practice-related courses have increased the popularity of the medicinal chemistry course for some students, although the majority were neutral in this regard. The number of different quizzes were found sufficient, however some verbal feedback from students has suggested increasing the number of quizzes as it was a good learning tool, in addition to gaining some extra marks. Although some of the surveyed students did not perform well in quizzes, all students agreed that the 'Postit Note' quizzes were effective in increasing your attention in the class. 
From the responses it can be concluded that the course has increased students' ability to identify the functional groups important for drug activity, which is an essential learning outcome of the medicinal chemistry course. The course was found to have improved the critical thinking and problem solving skills of $65 \%$ of the students. However at this stage we may consider the use of a more detailed tools in the future to measure the effect of the different changes on students' abilities.

The majority of students found medicinal chemistry relevant to other pharmacy courses and most students found that the pharmacy practice cases emphasised the importance of medicinal chemistry for their study and practice. However most students found that they would prefer to increase time taken to explain the cases in the lecture. The questions and revisions were found helpful in understanding the topic and preparing for the exams by only $68.2 \%$ of students.

Pharmacy practice cases were found to be relevant to other courses in the pharmacy curriculum by the majority of students and were considered helpful to relate the chemistry of the drug to practice. This has driven most students to suggest the integration of pharmacy practice cases in other medicinal chemistry courses and in other pharmacy curriculum basic sciences courses.

The main aim of incorporating a pharmacy practicerelated course to medicinal chemistry was to give the students an insight into the different roles played by the pharmacist, especially being the drug's chemistry expert in the medical team. The majority of students, while studying a chemistry course, were more able to perceive themselves as healthcare professionals. Although the interactive teaching methods were the tools that allowed for course improvement, many students did not see the benefits of such tools.

\section{Student performance}

Students' performance was assessed by students' marks in the different in-class activities, quizzes and exams, end of semester course evaluation questionnaire, and course ILOs achievement values. An improvement was observed in students' marks in all semesters, students scored higher marks in the quizzes as they proceeded with the course and as students are exposed to more cases and become more familiar with the new teaching techniques. Despite the significant enhancements to the course, some students still faced difficulties when tested both in the inclass quizzes and in the exams.

\section{Modification of course intended learning outcomes}

Driven by the modifications mentioned in this work and the introduction of 3D visualisation tools to the medicinal chemistry course, the course ILOs were modified over five years. These changes were to reflect the improvements in teaching, and assessment methods with a shift towards a more skills-based ILOs from the traditional knowledgebased ones. The basics of medicinal chemistry as presented to students in the form of SAR, and the effect of chemical structure modifications on potency, pharmacozkinetic properties, and/or toxicity were considered the knowledge part. The students' use of this knowledge part to understand the chemistry of other classes of compounds, and on making therapeutic decisions has shifted the ILOs into a more application-oriented learning. The relevant expected learning outcome is explained to the students after each case is presented and are linked to the ILOs listed in the course syllabus handed to them at the beginning of each semester.

The course ILOs achievement values improved over the years. In addition, the 'Course Evaluation' report, filled by all students enrolled in the course at the end of each semester, had shown an increase in the overall satisfaction of the course, class atmosphere, and the instructor's teaching and evaluation tools.

\section{Implementation}

The relevance of medicinal chemistry to pharmacy practice is not apparent to most pharmacy students. Students always question the number of chemistry courses they should pass before graduating, and how these courses would help them in their practice. Of the many challenges facing teaching basic sciences, it is the capability of providing the students with the strong foundation that is relevant to their pharmacy practice experience (Alsharif et al., 2008; Roche, 2009).

The pharmacy practice case studies presented in this work illustrated that the chemistry of a drug molecule plays a major role in a drug's effect, route of admiration, dosage form, pharmacokinetics, and/or safety, and hence the direct impact of these properties on therapeutic decision and clinical outcome. These cases gave the students an insight into the different roles of the pharmacist as the drug's chemistry expert in the medical team and they were more able to think of themselves as healthcare professionals.

Despite the enthusiasm to the introduction of pharmacy practice cases to the course, many students are still not 
feeling confident to apply this knowledge. It is believed that the methods described herein, once adopted, can considerably enhance students' fundamental knowledge that can be latter enforced in other courses in the curriculum, and when they start to practice.

In this course, the authors did not cover (and it is impossible to do so) every case scenario that a pharmacist could encounter during practice, however they succeeded in encouraging the students and helped them to improve their learning process and provided them with insights on the relationship between the drug's chemistry and its therapeutic effect and/or clinical use.

The interactive teaching methods incorporated in the course such as use of 3D visualisation, 'Post-it-Note' quizzes, and group discussions, had created a more dynamic classroom environment. Most of the students, if not all, were involved in the problem solving process despite the large number of students in each class. The discussions encouraged them to think and sometimes think differently as no answer is wrong if the rationale behind it is coherent. The improvement of students' achievement and course satisfaction, measured by the different assessment tools, showed that the interactive teaching methods have helped the students to understand the importance of medicinal chemistry to their practice. However, as the study suggests, more time should be allocated for case discussion and more tools should be used to encourage critical thinking and problem solving skills.

The clinical cases presented in this work were found to be an effective tool to help students understand the basic concepts, and practical applications of medicinal chemistry. However, major changes are required in pharmacy curricula to integrate the practice part of the pharmacy profession to all basic science courses. When talking about medicinal chemistry, maybe it is time to introduce the concept of clinical medicinal chemistry to pharmaceutical sciences in which more of the practical aspects of drug chemistry are covered.

\section{Acknowledgments}

I wish to thank my students whom I learned from more than they learned from me.

\section{References}

Alsharif, N.Z., \& Galt, K.A. (2008). Evaluation of an Instructional Model to Teach Clinically Relevant Medicinal Chemistry in a Campus and a Distance Pathway. American Journal of Pharmaceutical Education, 72(2), 1-11. https://doi.org/10.5688/ aj720231

Beleh, M., Engels, M., \& Garcia, G. (2015). Integrating a new medicinal chemistry and pharmacology course sequence into the PharmD curriculum. American Journal of Pharmaceutical Education, 79(1), 13-13. https://doi.org/10.5688/ajpe79113

Carvalho, I., Borges, Á.D.L., \& Bernardes, L.S.C. (2005). Medicinal Chemistry and Molecular Modeling: An Integration To Teach Drug Structure-Activity Relationship and the Molecular Basis of Drug Action. Journal of Chemical Education, 82(4), 588-596. https://doi.org/10.1021/ed082p588

Crofford, L.J. (1997). COX-1 and COX-2 tissue expression: implications and predictions. The Journal of Rheumatology, 49, $15-19$

Dassault Systèmes BIOVIA. (2017). BIOVIA Discovery Studio Visualizer. Release 2017 R2, , San Diego: Dassault Systèmes

Deshpande, A.D., Baheti, K.G., \& Chatterjee, N.R. (2004). Degradation of $\beta$-lactam antibiotics. Current Science, 87(12), 1684-1695

Fini, A., Fazio, G., Hervás, M.-J. F., Holgado, M. A., \& Rabasco, A. M. (1996). Factors governing the dissolution of diclofenac salts. European Journal of Pharmaceutical Sciences, 4(4), 231-238. https://doi.org/10.1016/0928-0987(95)00051-8

Fong, C.W. (2015). Permeability of the Blood-Brain Barrier: Molecular Mechanism of Transport of Drugs and Physiologically Important Compounds. The Journal of Membrane Biology, 248(4), 651-669. https://doi.org/10.1007/s00232-015-9778-9

Gupta, D., Bhatia, D., Dave, V., Sutariya, V., \& Varghese Gupta, S. (2018). Salts of Therapeutic Agents: Chemical, Physicochemical, and Biological Considerations. Molecules (Basel, Switzerland), 23(7), 1719-1734. https://doi.org/10.3390/molecules23071719

Johnson, D.A. (2003). Review of esomeprazole in the treatment of acid disorders. Expert Opinion on Pharmacotherapy, 4(2), 253-264. https://doi.org/10.1517/14656566.4.2.253

Lemke, T.L., \& Williams, D.A. (2007). Principles of medicinal chemistry, Foye's. Philadelphia: Lippincott Williams \& Wilkins

McPherson, M.L., \& Cimino, N.M. (2013). Topical NSAID Formulations. Pain Medicine, 14(Sup.1), S35-S39 https://doi.org/ 10.1111/pme.12288

Patrick, G.L. (2017). An introduction to medicinal chemistry. Oxford University Press, UK. https://doi.org/10.1093/actrade/ 9780198759775.003.0001

Roche, V.F. (2009). A receptor-grounded approach to teaching nonsteroidal antiinflammatory drug chemistry and structureactivity relationships. American Journal of Pharmaceutical Education, 73(8), 143-143. https://doi.org/10.5688/aj7308143 
Roy, J. (2011). An Introduction to Pharmaceutical Sciences: Production, Chemistry, Techniques and Technology: Elsevier Science

Satyanarayanajois, S.D. (2010). Active-Learning Exercises to Teach Drug-Receptor Interactions in a Medicinal Chemistry Course. American Journal of Pharmaceutical Education, 74(8), 147-156. https://doi.org/10.5688/aj7408147

Sidhu, R.S., Lee, J.Y., Yuan, C., \& Smith, W.L. (2010). Comparison of Cyclooxygenase-1 Crystal Structures: Cross-Talk between Monomers Comprising Cyclooxygenase-1 Homodimers. Biochemistry, 49(33), 7069-7079. https://doi.org/10.1021/ $\underline{\text { bi1003298 }}$

Shin, J.M., Munson, K., \& Sachs, G. (2011). Gastric H+,K+ATPase, Comprehensive Physiology, 1(4), 2141-2153. https:// doi.org/10.1002/cphy.c110010

Vane, J.R., Bakhle, Y.S., \& Botting, R.M. (1998). CYCLOOXYGENASES 1 AND 2. Annual Review of Pharmacology and Toxicology, 38(1), 97-120. https://doi.org/10.1146/ annurev.pharmtox.38.1.97

Varga, Z., Sabzwari, S.R.A., \& Vargova, V. (2017). Cardiovascular Risk of Nonsteroidal Anti-Inflammatory Drugs: An UnderRecognized Public Health Issue. Cureus, 9(4), e1144-e1144. https://doi.org/10.7759/cureus.1144

Wallace, S.M., \& Chan, L.Y. (1985). In vitro interaction of aminoglycosides with beta-lactam penicillins. Antimicrobial Agents and Chemotherapy, 28(2), 274-281. https://doi.org/ $\underline{10.1128 / A A C .28 .2 .274}$

Wang, J.L., Limburg, D., Graneto, M.J., Springer, J., Hamper, J.R. B., Liao, S., et al. (2010). The novel benzopyran class of selective cyclooxygenase-2 inhibitors. Part 2: The second clinical candidate having a shorter and favorable human half-life. Bioorganic \& Medicinal Chemistry Letters, 20(23), 7159-7163. https://doi.org/ $\underline{10.1016 / \text { i.bmcl.2010.07.054 }}$

Wermuth, C.G., Ganellin, C.R., Lindberg, P., \& Mitscher, L.A. (1998). Glossary of terms used in medicinal chemistry (IUPAC Recommendations 1998). Pure and Applied Chemistry, 70(5), 1129-1143. https://doi.org/10.1351/pac199870051129

\section{Appendix A}

Medicinal Chemistry Quiz

During your work as a pharmacist, you were presented with the following drug $A$ :
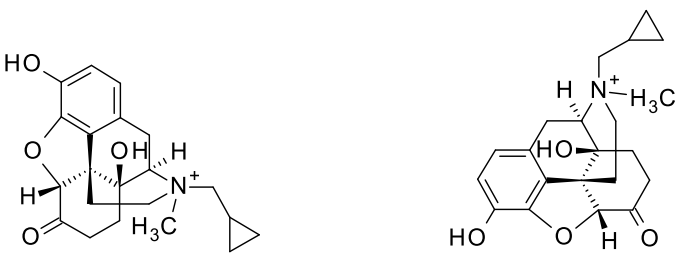

Drug A

From what you learned about the Opioids' structure activity relationship, answer the following:

1. The drug:

(Circle the right answer and explain why):

A. Is an Agonist or Antagonist:

B. Acts in: the Central Nervous System or Periphery:

2. Suggest a therapeutic use for this drug: 